\title{
A Pre-Peanut History of Food Allergy
}

\author{
Matthew Smith \\ University of Strathclyde
}

\begin{abstract}
:
Since 1990, food allergy has become synonymous with anaphylactic reactions associated with shellfish, milk, and, especially, peanut allergy. Rates of food allergy have mushroomed, contributing to changes in how food is produced, marketed, and consumed. Concerns about peanut allergy have changed what schoolchildren can have for lunch, affected how foods are processed and labelled, and led to the banning of peanut products in numerous public spaces. Food allergy is not new, but the seriousness with which it is treated is. For much of the twentieth century food allergy was a perplexing, dubious, and controversial concept that both divided and threatened allergists. I suggest this was due to: 1) the theoretical, diagnostic, and therapeutic challenges raised by food allergy; 2) the claims food allergists made about the scope and extent of their subject; and 3) the threat food allergy and food allergists posed to the scientific legitimacy of allergy.
\end{abstract}

Keywords: history; food allergy; medicine; food; peanuts; anaphylaxis

\section{Introduction}

In May 2005, the Ontario legislature took the rare step of passing a private member's bill proposed by Member of the Provincial Parliament, Dave Levac. Bill 3, nicknamed 'Sabrina's Law," was inspired by the death of Sabrina Shannon, a 13 year old student who died of anaphylactic shock after eating cafeteria French fries contaminated with dairy products, to which she was allergic. Although the French fries themselves had not contained any dairy, they had been placed on Sabrina's plate with tongs used previously to serve poutine, a 
Quebecois dish containing milk products. The resulting law required schools across the province to establish prevention and contingency plans for all students afflicted with anaphylactic allergies, and train all school staff how to recognize and respond to cases of anaphylactic shock. ${ }^{1}$

While Sabrina's Law was inspired by a fatal case of milk allergy, the food allergy most feared and most discussed for the last twenty years has been peanut allergy. For reasons that allergists and immunologists continue to debate, rates of peanut allergy have mushroomed since the early 1990s, fomenting legislative and industrial action to prevent accidental exposure. $^{2}$ Companies such as Mars Canada, for example, have undertaken advertising campaigns based on their claim that their chocolate bars are made in nut-free facilities. The Canadian Food Inspection Agency, as well as the American Food and Drug Administration, have also taken strong steps to ensure that consumers can identify easily whether or not packaged food contains common allergens, such as peanuts. ${ }^{3}$

To a degree, fears about peanut allergy are well-founded. Approximately one million North Americans are allergic to peanuts, and while exposure to peanuts might only cause mild symptoms, some people suffer severe anaphylactic reactions, reactions that are fatal approximately one hundred times per year in the US. Stories about tragic, yet often bizarre, reactions to peanuts have fueled public interest in peanut allergy and contributed to aggressive public health responses. A recent story, for example, claimed that a fifteen-year-old Quebec girl died of anaphylactic shock after kissing her boyfriend, who had recently eaten a peanut butter sandwich. ${ }^{4}$ Although the coroner was unable to prove that the kiss was the source of the allergen, in another Quebec case, an eighty year old woman developed a peanut allergy after being given a blood transfusion from someone with peanut allergy. ${ }^{5}$ The case made 
doctors wonder if blood donors should be screened for allergies. ${ }^{6}$ That the humble peanut could cause such concern is partly a testament to the strange and shocking nature of these stories, but also the prominence of peanuts and peanut products in the diet of so many young people. Tapping into such concerns lobbyists have successfully called for the meticulous labeling of peanut products, increasingly making schools, airplanes, and even sports facilities, such as Edmonton, Alberta's Commonwealth Stadium, peanut-free zones. ${ }^{7}$ Although the demonization of peanuts during the past two decades has been primarily a North American phenomenon, concern about peanut allergy is increasing elsewhere, particularly in Europe and Australia. $^{8}$

Such vigilance makes it difficult to think of food allergy without the peanut and the accompanying fear of anaphylactic reactions. Indeed, the history of food allergy, pre-peanut, has been either ignored or forgotten by allergists, contributing to a simplistic and possibly limited understanding of food allergy. This could be due, in part, to the fact that food allergy has been unexplored by historians. While a small number of scholars, most notably Mark Jackson and Gregg Mitman, have begun to analyze the broader history of allergy and contribute to the broader debates about allergic disease, there has been very little written about food allergy. ${ }^{9}$ When the history of food allergy has been considered, there has been little attempt to critique how both medically legitimate and unorthodox understandings about food allergy have developed over time and have been shaped by cultural, economic, and political factors. ${ }^{10}$ Instead of accepting either dominant or marginalized definitions of and explanations for food allergy unquestioningly, it is perhaps more helpful to do as Jackson has done in his work on allergy, and examine why differing conceptualizations of food allergy have emerged and what this says about our understanding of immunology and nutrition more generally. ${ }^{11}$ 
When the early, pre-peanut history of food allergy is examined in earnest, many differences emerge between current understandings of food allergy and how reactions to food were dealt with during most of the twentieth century. Today, our notion of food allergy revolves around the immediate, anaphylactic, possibly fatal, and easily traceable reactions that sufferers exhibit when they are exposed to allergens such as peanuts. In contrast, earlier food allergists, the subset of allergists who were convinced that allergies to foods were a common cause of otherwise unexplained health problems, were not as concerned with peanuts or the types of severe reactions they could cause. Instead, they dealt primarily with the delayed, lingering, chronic, and elusive reactions that could manifest themselves in symptoms ranging from gastrointestinal and respiratory problems to dermatological and neurological complaints. Peanuts were rarely listed as a common cause of food allergy until the late 1980s, and were not considered exceptionally allergenic prior to then. Rather, milk, wheat, eggs, and potatoes were commonly-cited culprits, along with food additives. Although clinicians did come across anaphylactic reactions, they treated delayed, chronic reactions more often. Confusing the issue somewhat is the fact that the term anaphylaxis, coined by Charles Richet and Paul Portier in 1902, was used instead of Clemens von Pirquet's 1906 term, “allergy" until the 1920 s, when its use was restricted to what is now known as anaphylaxis. ${ }^{12}$

Perhaps more striking than these differences in symptomatology, however, is the difference in the respect given to food allergy and food allergists by allergists during these two phases in the history of food allergy. While today's food allergy is deemed to be serious and authoritative enough to warrant private member's bills, strict labeling legislation, and peanutfree spaces, earlier allergists believed that "controversy rages around the clinical importance and frequency of food allergy in a more lively manner than around any other subject in the 
field of allergy." 13 In what follows I examine this early history of food allergy, and attempt to explain why the subject became so divisive. At the heart of such controversy were not only methodological problems concerning the diagnosis and treatment of food allergy, but also issues related to the manner in which claims about food allergy were made, as well as how these claims reflected on allergy as a whole. The history of food allergy is a story of competing ideologies, political agendas, and different approaches to what constitutes medical knowledge. Although food allergy, symbolized by anaphylactic peanut allergy, has become a potent public health issue, it is important to realize that other, equally legitimate approaches to food allergy existed and found favor. Before dismissing older, more controversial conceptualizations of food allergy out of hand, both allergists and their patients should consider why such ideas became popular and why they were ultimately rejected.

"The subject does not lend itself to an easy solution"

For much of the twentieth century, allergy was a controversial subject amongst medical practitioners, occupying a tenuous position on the medical hierarchy. As Tennessee allergist William Crook contended, despite the fact that "allergy celebrated its golden anniversary in $1956 \ldots$ [and] is as old, or older, than many other branches of medicine, it occupies a uniquely confusing and controversial position. No other field of medicine has been the subject of as much violent controversy, difference of opinion and confusion." ${ }^{14}$ In lamenting the lack of respect and resources accorded to the discipline, the authors added that "too often allergy is regarded as witchcraft, a fad or a racket. In this respect, allergy has had to fight some of the same battles that psychiatry has been fighting." 15 Similarly to psychiatrists, most allergists believed that other physicians viewed their discipline as scientifically questionable, lacking in laboratory evidence, and over-reliant on clinical observations. Allergists also 
thought that allergic illness was more widespread and was responsible for a wider array of symptoms than was commonly thought, which also mirrored psychiatric fears about the prevalence of mental illness. Despite these broad concerns allergists, again like psychiatrists, argued amongst each other about the extent of these problems and how to solve them.

Central to these debates were fundamental issues related to how allergy should be defined, treated, and conceptualized, and food allergy had the longest history of causing fractious disagreements. One reason for this was the difficulty in defining what constituted an allergic reaction to food. Proponents of food allergy claimed that the condition was common and multi-symptomatic, responsible for causing everything from migraine and asthma to diarrhea and eczema. In contrast, orthodox allergists, who believed that allergies could only be proven by a clearly demonstrated immunological response, believed that "true food allergy," where such responses were evident, was rare. Such divisions affected clinical practice, including both the diagnosis and treatment and patients.

Some of these twentieth-century debates had precursors in the previous century. Prior to the coining of the term allergy in 1906, it was relatively common for physicians to attribute otherwise unexplained symptoms to food their patients had ingested, reactions commonly called idiosyncrasies. In some cases, idiosyncrasies to foods such as eggs, seafood, and strawberries were experienced immediately, acutely, and severely, bearing many of the hallmarks of anaphylaxis, including vomiting, heart failure, loss of consciousness, and even death. ${ }^{16}$ But physicians also recorded perplexing chronic reactions to foods. While New Yorker Louis Fischer reported gastrointestinal symptoms from ingesting foods such as milk or eggs, others thought that food idiosyncrasies could cause respiratory troubles. ${ }^{17}$ In 1858 , for example, London physician and Fellow of the Royal College of Physicians, Henry Hyde 
Salter (1823-1871), described how asthma attacks, from which he suffered himself, could be triggered by foods, particularly those "in any way preserved, ... such as potted meats, dried tongue, sausages, stuffing and seasoning ... preserved ginger, candied orange-peel, dried figs, raisins - especially almonds and raisins (a vicious combination.)" Hyde Salter proceeded to list cheese, nuts, meat pies, coffee, and malt liquors as also being especially "asthmatic."18

Although subsequent food allergists would cite asthma as a symptom of food allergy, the most common reactions described by nineteenth-century physicians were dermatological, including urticaria (nettle rash or hives), eczema, purpura (a purplish rash), and pruritis (itching). Scottish medical professor McCall Anderson believed that nettle rash could be caused by idiosyncrasies to a wide range of foods, including shellfish, fruits, nuts, vegetables, wheat, cocoa, and various kinds of meat. One of his relatives, who claimed to suffer from an idiosyncrasy to meat, but not poultry, wrote that if Anderson "made it worth my while, I will come down at the Whitsuntide holidays and be exhibited. I will also eat the Ornithorhynchus paradoxus [platypus] ... and finally determine whether it be bird or beast." 19

Others, however, were not convinced about the link between food and dermatology. As Londoner Stephen Mackenzie contended in 1896, there 'is probably no subject in which more deeply rooted convictions have been held, not only in the profession but by the laity, than the connection between diet and disease. ... In diseases of the skin we have admirable examples of faulty conclusions that have been drawn." ${ }^{20}$ Mackenzie proceeded to highlight eczema, stating that 'no disease of the skin has diet been more blamed ... than in eczema. Infantile eczema we constantly find ascribed to faults in diet ... but there is no evidence to connect them with eczema as cause and effect." 21 Walter Smith, Fellow of the Royal College of Physicians of Ireland, concurred: 
Have we any certain or exact scientific knowledge of the influence of diet in the causation of diseases of the skin? The belief in the potency of this influence is universal with the laity, and widely acknowledged by the profession generally. But the practice of physicians is partly traditional and is, unfortunately, not always based upon real conviction or sound knowledge, and many circumstances conspire to tempt them to give formal advice which rests upon a slender foundation. ${ }^{22}$

Scottish physician W. Allan Jamieson echoed Smith's concerns that public belief in the link between diet and dermatology posed diagnostic difficulties:

We must reject in large measure the statements volunteered by our patients, though we thereby get much information. ... The patient in nearly all cases ascribes an immediate effect to his diet, though it may be obvious on the least reflection that the action, if exerted at all, must be remote. ${ }^{23}$

Such concerns about the reliability of patient testimony, and the difficulty in diagnosing food idiosyncrasy generally, did not diminish following the establishment of allergy as a distinctive medical condition in the early twentieth century. Pondering the topic in a review of a 1950 food allergy textbook, New York City allergist and former American Academy of Allergy (AAA) president Will Spain echoed Jamieson's earlier comments:

Of all the problems in clinical sensitization ... food allergy is the most difficult to resolve. There are three potent reasons for this: first, the patient lacks objectivity in presenting his problem because of his whims, fancies, and aversions relating to various viands ...; second, the physician, shorn in at least half of his cases of the benefit of positive food reactions by skin test, tends to be influenced unduly by the description made by the patient ...; and third, thanks to the ability of food allergy to mimic many other nonallergic complaints, the actual allergic nature of the particular problem remains debatable and unsettled. ${ }^{24}$ 
Although Spain was sympathetic to the authors' approach to food allergy, he warned that their methods were:

time-consuming, tedious, and complicated. But so is the condition of food allergy complicated. Anyone in search of a simple and easy diagnostic procedure for this clinical form of sensitization will not find it in this volume nor elsewhere. The subject does not lend itself to an easy solution. ${ }^{25}$

The ways in which food allergists responded to these difficulties contributed significantly to why food allergy was such a controversial topic. As Spain noted, allergists were more reliant on patient testimonials when dealing with suspected food allergies, than when treating allergies caused by pollen, animal dander, or dust mites. This was because, as he indicated, skin-tests were not believed to be an effective diagnostic tool for identifying food allergies. With most allergies, skin-testing was a quick, accurate, and relatively safe way to determine which substances were responsible for causing allergic reactions in patients. The procedure, pioneered by von Pirquet in 1907 to test for reactions to tuberculin, an antigen used in inoculations for tuberculosis, involved depositing a small amount of the potential allergen just below the skin and then waiting to see if the skin erupted in a wheal, a swollen, reddish eruption. It soon became the primary means by which allergists identified allergens and assessed their severity: the more potent the allergen, the larger the wheal.

By the 1910s and 1920s, allergists were inclined to believe that food allergies could be detected by skin tests. In an article on the neurological manifestations of food allergy in children, Minnesota physician W. Ray Shannon described using skin tests successfully, as did others. ${ }^{26}$ Nevertheless, the practice was controversial. One good reason for this was that food 
allergy skin tests could provoke powerful allergic reactions. In 1921, for example, two Cleveland pediatricians employed skin tests to discover what was causing a one-year-old child's eczema and asthma. Following inoculations of egg, the child not only developed a large wheal at the site of the injections but also experienced "severe and extreme" breathing difficulties and cyanosis (turning blue), to the point that epinephrin had to be administered. ${ }^{27}$ This did not convince them, however, that egg was the culprit and, a few days later, they inoculated him again with egg. Apparently confident that no reaction would occur, the resident physician left the room, along with the nurse, only to discover five minutes later that the child had stopped breathing. Epinephrin was employed again and the child recovered. Although the moral of the story according to the authors was merely to have epinephrin nearby when performing skin tests, such shocking accounts made allergists wary of using such tests for suspected food allergy.

There was also a growing perception that skin tests were simply not very good indicators of food hypersensitivity. ${ }^{28}$ As early as 1920 , clinicians were being warned that the "results of cutaneous sensitization tests are occasionally spectacular. On the other hand, they are much of the time indeterminate or highly confusing." 29 As gastroenterologist and medical columnist Walter Alvarez described, "even the allergists admit that in cases offood sensitiveness skin tests are unreliable and only occasionally give a helpful hint." ${ }^{20}$ Such tests not only failed to identify problematic foods, but in some cases, "the skin reacts to substances never ingested or to ingestants which provoke no clinical symptoms." ${ }^{31}$ By the middle of the century, prominent food allergists such as Albert Rowe, Theron Randolph, and Arthur Coca had all rejected the use of skin tests for food allergy, developing elimination diets instead as diagnostic tools. ${ }^{32}$ Patients would be prescribed a limited, hypoallergenic diet, and then reintroduce suspected foods one by one to see if they provoked a reaction. 
Without skin tests, food allergists had to rely on the recollections of their patients, as well as their own clinical experiences, to diagnose food allergy. As Spain indicated, the lack of more objective diagnostic procedures led to skepticism from critics about the claims food allergists made about the scale of food allergy. ${ }^{33}$ New York pediatrician Walter Kessler, for example, believed that food allergists were too willing to accept patients' accounts at face value. Complaining that he was "constantly confronted by infants whose parents consider their behavior as being outside the realm of normal, and where the diagnosis of 'allergy to some food' has already been made by the parent prior to consultation with the physician," Kessler asserted that such cases were not examples of allergy, but rather of "food intolerance."34 Food allergists, he argued, were all too willing to use "food allergy as a 'scrap-basket diagnosis' for a variety of problems, for which no other diagnoses have been found." ${ }^{35}$ The root of the problem for Kessler was the difficulty in proving the antigen-antibody reaction in cases of food allergy. If the antigen-antibody reaction could not be demonstrated, via the use of a skin test, for example, then the patient was suffering from food intolerance, not food allergy.

Essentially, the difference between food allergy and intolerance amounted to contrasting definitions of allergy. Kessler believed that "instances of true food allergy do occur," but insisted that in such cases allergists should be able "to demonstrate an immunologic reaction ... [that] serves to confirm, and give objective evidence for, allergy as the underlying mechanism." ${ }^{36}$ Although Kessler admitted elsewhere that it was not always possible to demonstrate such immunological mechanisms in food allergy, through the use of skin tests, for example, he nonetheless restricted his definition of allergy to cases in which such a mechanism could be clearly shown, demonstrating that antibodies had been produced to 
defend the body against what the immune system deemed an invasive foreign protein. ${ }^{37}$ Fellow pediatrician Edward Pratt also demanded a narrower definition of allergy, contending that von Pirquet's description of allergy, as "any form of altered biological reactivity," which food allergists preferred, "could encompass practically any disturbance, including those in interpersonal relations. For example, there would be more fact than humor in the saying, 'He is allergic to his mother-in-law.", 38

Food allergy also required a different form of treatment than most other allergies. Skin tests were not only diagnostically useful, but also provided allergists with the necessary information for desensitization therapy, "the cornerstone of their allergy practice." 39 Desensitization emerged in the early twentieth century in the UK and USA as an offshoot of vaccine therapy, the use of weakened strains of bacteria to treat active infections such as typhoid, cholera, and tuberculosis. Treatment involved inoculating patients over time with small, but increasing, amounts of allergen extract in order to build up tolerance to allergens such as pollen, dust, and dander.

Although food desensitization did occur, opinions were divided about its effectiveness. ${ }^{40}$ While some, such as New York gastroenterologist Edward Hollander, successfully desensitized patients to commonly-eaten foods, others warned that desensitization could be dangerous and ineffective. ${ }^{41}$ Pediatric allergist Bret Ratner, for example, argued that in severe cases "it is futile to hope for any beneficent results to accrue from desensitization." 42 Instead clinicians should prescribe the "rigid elimination of all offending substances" and, in cases involving children, involve "the most complete cooperation of a very intelligent mother." George Piness and Hyman Miller agreed that eliminating "foods has been found far more advisable than attempted immunization" and could lead to prolonged immunity. ${ }^{44}$ 
The inability of food allergists to use desensitization as a reliable treatment for food allergy served as another indication that food allergy was distinct from mainstream allergy.

Desensitization was based in immunological theory and linked both conceptually and historically to vaccination and the notion that immunity could be built up by repeated doses of a weakened pathogen. The problems inherent in desensitizing food allergy sufferers indicated that food allergy had trouble fitting into the established immunological framework.

Moreover, the idea behind desensitization was that it was the idiosyncratic patient, not the patient's environment, that should be altered. Hay fever suffers might try to alter their environment, staying indoors during pollen season, but they were effectively the passive recipient of the desensitization provided by the allergist. Food allergists, in contrast, provided expert knowledge to their patients, but it was the patient who was ultimately responsible for purchasing, preparing, and eating the foods allowed in their elimination diet.

The ineffectiveness of desensitization treatment for food allergy alienated food allergists from their peers in another way; it meant that they were somewhat removed from what Jackson has called the "global economy of allergy," the wide range of anti-allergy products developed by the pharmaceutical industry to treat the condition. ${ }^{45}$ Desensitization meant not only the provision of a medical service, but also the development and provision of a product, namely extracts of various allergens. Gregg Mitman has described how American pharmaceutical companies quickly exploited desensitization techniques developed during the 1910s, and undertook extensive pollen surveys across the United States to identify the most problematic plant allergens. ${ }^{46}$ The resulting extracts were sold to allergists for use on hay fever patients. Desensitization, as well as other allergy treatments, such as antihistamines, corticosteroids, and bronchodilators, - rarely used by food allergists - linked the work of allergists with the 
research, marketing, and sales activities of major pharmaceutical companies. ${ }^{47}$ Although allergists may have debated, for example, the respective merits of corticosteroids and desensitization extracts, the sale of either was an example of the symbiotic relationship that existed between allergist and pharmacist. ${ }^{48}$

Food allergists, however, enjoyed no such relationship with pharmaceutical companies. Rather than involving the purchase of a medical product, elimination diets restricted what patients could purchase and encouraged them to shop more cautiously. This was especially the case for Theron Randolph's patients who, by the 1950s, were encouraged to purchase unprocessed, organic, and pesticide-free foods. ${ }^{49}$ Randolph admitted that to "name corn, wheat, milk, eggs, beet and cane sugar as the sources of illness, even in a minority of the population, will not make many friends among the commercial producers of these foods." ${ }^{50}$ In addition, the tendency for food allergists to claim that food allergy caused a great number of ailments misdiagnosed by other physicians meant that food allergists diverted patients from the products developed by pharmaceutical companies to treat such complaints. Hypoallergenic foodstuffs were developed and marketed for people who were allergic to staples such as milk, egg, and wheat (for example, Ditex Oat Crisps, biscuits free of egg, milk, wheat, corn and barley), but food allergists rarely advocated such products. Food allergists such as Randolph instead appealed to food producers to provide clear, comprehensive, and accurate lists of ingredients on their product labels, a request that placed greater demands on industry with little or no benefit in return.

Without the use of skin tests, desensitization, or pharmaceutical intervention, food allergists shared little in common with their fellow allergists in terms of clinical practice. Employing broad, expansive definitions of allergy that drew on von Pirquet's 1906 terminology, food 
allergists were also theoretically distinct from more orthodox allergists, who believed that most so-called food allergies were not immunological at all, and were instead examples of mere food intolerance or psychosomatic manifestations. These clinical and theoretical differences created a gulf between food allergists and their conservative colleagues, contributing to the divisive nature of food allergy. Equally crucial, however, was the manner in which food allergists presented food allergy and its importance to the wider medical community in explaining a wide range of chronic, undiagnosed symptoms.

Food allergy: 'The commonest form of human allergy'?

Debates about food allergy during the twentieth century tapped into nineteenth-century discourses about the prevalence of food idiosyncrasies and older dialogues about the role of nutrition in health. Seemingly aware that it was a sensitive topic, Detroit pediatrician, B. Raymond Hoobler, discussed the topic tactfully. In a 1916 paper on how foods could cause irritability, restlessness, and insomnia in children, Hoobler stressed:

I am well aware that many of the symptoms named [sneezing, coughing, wheezing, vomiting, irritability, restlessness, fretful, insomnia, eczema] are symptoms of other very common diseases, and it is not my desire to claim that they occur only as symptoms of protein sensitization [food allergy]; but it is my observation that when the group of symptoms as outlined occurs and reoccurs in an infant early in its existence, that one should be on guard and should carefully watch for further developments. ${ }^{51}$

Hoobler's caution was not indicative of how most food allergists discussed their subject. Instead the notoriety of food allergy was due in large part to the unbridled enthusiasm its proponents expressed for its prevalence and significance. Albert H. Rowe (1889-1970), who operated a highly profitable Bay Area clinic, contended not only that foods "probably produce 
more allergic manifestations in various tissues of the body than any other group of allergens," but also that such allergies caused a boundless array of symptoms, ranging from diarrhea to epilepsy. ${ }^{52}$ According to Rowe , the failure "of the majority of physicians and specialists, including most allergists, to recognize, study, and control such allergies is in our opinion one of the main deficiencies in medical practice today." 53

Rowe's zeal was echoed by others. In his provocative book, Allergy: Strangest of all Maladies, Warren T. Vaughan stated that: "Sensitization to foods is the commonest form of human allergy," contributing significantly to the allergies suffered by, as Vaughan further claimed, 60 per cent of the US population. ${ }^{54}$ Vaughan's rationale for such high rates helps to explain why food allergy was so perplexing. According to him, food allergy sufferers could be divided into two distinct categories: the "frank allergic," and the "fortunate allergic." 55 The frank allergic were distinguished by their inability to identify the source of their allergy, often because it was caused by a staple, such as wheat, milk or egg. The ubiquity of such foods not only made them difficult to identify but also meant the frank allergic constantly suffered from unexplained reactions. ${ }^{56}$ Bewildered by their symptoms, they sought medical advice and represented the majority of allergy sufferers seen by physicians. The fortunate allergic, in contrast, were allergic to less common foods, such as "cucumber, watermelon, strawberry, tomato, onion, and cabbage," which were easier to identify and avoid. ${ }^{57}$

Vaughan's dichotomy of the fortunate and frank allergic differed greatly from distinctions made by other allergists who divided food allergies into those involving immediate and delayed reactions. Such discrepancies were somewhat understandable, given that, as Jackson has demonstrated, allergists devised many different ways to classify allergy, including classification by organ system affected or by underlying immunologic mechanism. ${ }^{58}$ 
Vaughan's unorthodox division, however, highlighted the premium food allergists placed on clinical observation, namely, the knowledge they gained from treating patients, as opposed to immunological theory, what laboratory and academically-based allergists and immunologists believed about how the immune system functioned. According to a contemporary internist, "the present diagnosis of food hypersensitivity rests almost exclusively on clinical observation." ${ }^{59}$ As allergy strove to gain more respect from the medical community, for example, attaining status as a board-certified profession distinct from pediatric and internal medicine, food allergists' emphasis on inductive reasoning and drawing conclusions on the basis of clinical encounters fell into disfavor. In 1961, for example, Francis Lowell, editor of the Journal of Allergy, singled out food allergists for their over-reliance on clinical observations. According to Lowell, such evidence would not advance the state of allergy, rather "such impressions should be put to the test by well thought out experiment."60

Nevertheless, clinical and personal experiences remained a powerful heuristic for many food allergists, including Arthur Coca (1875-1959). Coca's early career was characterized by academic, rather than clinical, work, serving as professor at Cornell Medical School from 1910-1932 and the medical director of Lederle Laboratories. Motivated by his own health problems, such as severe migraines, dizziness, and hypertension, however, he turned to food allergy later in his career. ${ }^{61}$ Recognizing the ineffectiveness of skin tests for food allergy, he turned to other diagnostic procedures including pulse tests, after discovering that his wife's heart raced when she ate certain foods. ${ }^{62}$ Coca echoed Vaughan's contention that most people suffered from minor allergy, believing that Vaughan's 60 per cent figure was “somewhat conservative." 
When Coca's claims are examined, it is not surprising that he believed Vaughan's underestimated the extent of food allergy. Coca's list of food allergy symptoms not only included commonly-listed complaints, such as chronic fatigue, mental disturbance, and headaches, but also more provocative symptoms including high blood pressure, baldness, the common cold (one of his chapters was entitled: "You don't catch your colds - you eat them"), certain types of cancer, multiple sclerosis, glaucoma, and even the tribulations of old age. In The Pulse Test for Allergy, he mused that the "problem of old age will surely change when the new knowledge of food-allergy is put to universal use. Instead of planning for the care of the 'aged,' we shall have to find the work for them which they will certainly demand in their emancipation from the allergic handicap." ${ }^{\prime 64}$

Other food allergists were provocative in different ways. Although Theron Randolph's assertion that food allergies could cause many chronic symptoms mirrored claims made by other food allergists, his contention that most of his patients were chronically ill due to pollutants in their food, air, and water was politically and medically controversial. ${ }^{65}$ Randolph (1906-1995) also prompted the ire of the food industry by recommending to the Food and Drug Administration in 1949 that food products have more detailed labels to prevent allergic reactions. ${ }^{66}$ Richard Mackarness (1916-1996), a British psychiatrist who believed food allergies could cause mental illness, considered Randolph his greatest influence, and similarly asked pointed questions about the relationship between pollution, allergy, and health. Echoing Rowe's earlier comments, Mackarness argued that allergy, "was the greatest cause of illness in Westernized society" and singled out "the industrialized production of food" as the prime explanation for its rise. ${ }^{67}$ 
One might assume that such vitriolic statements were made by marginalized, parochial clinicians who lacked authority. In reality, however, many food allergists were leaders in the allergy community, and this added weight to their claims. Rowe had been president of the American Association for the Study of Allergy (AASA) in 1929, as was Vaughan, who was also president of the Society for the Study of Asthma and Allied Conditions (SSAAC) in 1938. Vaughan's father, Victor Vaughan (1851-1929), who also investigated food allergy, was the dean of the University of Michigan Medical School between 1891 and 1920, president of the American Medical Association (1914-1915), and a leading medical figure during the Progressive Era. ${ }^{68}$ Coca was also a president of the SSAAC (1931), but more significantly founded the Journal of Immunology and edited it for 32 years. In conjunction with pioneering allergist Robert A. Cooke, Coca coined the term atopy, a tendency to inherited acute hypersensitivity, in $1923 .{ }^{69}$ Many of the food allergists who made seemingly outrageous claims about food allergy, therefore, were also seen as allergy pioneers. As such, not only did their research get published in leading allergy journals, but it also found support along with criticism. This, if anything, only added to the notoriety of food allergy, and increased the gulf between food allergists and their more conservative colleagues.

'With What We must Contend': Legitimizing Allergy

Although orthodox allergists disagreed with food allergists on theoretical and clinical grounds, the legitimacy of allergy was also at stake. Allergists had long bemoaned their discipline's lack of respectability and feared that their specialized services might be assumed by other physicians, such as dermatologists or pediatricians. ${ }^{70}$ Allergists were also troubled by the perception that allergy, like psychiatry, was more art than science. According to Max Samter, speaking at his presidential address to the AAA in 1960, the 'art of allergy which we 
practice is based on tradition - the joint experience of generations of allergists. Experience, however, is only the beginning; the art of allergy must now be persuaded to adopt and perhaps to be altered by its own unruly offspring, the science of allergy."71 In other words allergists had to venture beyond routine clinical practice and learn from the laboratory.

Prominent allergists also recognized the difficulty in attracting "high grade men" to specialize in allergy and complained "that many young internists have been permitted to finish their training without contact with allergy and allergic thought."72 Exacerbating matters were political disputes between the AAA, dominated by conservative academics whose beliefs about allergy were rooted in immunological theory and laboratory evidence, and the American College of Allergy (ACA), represented by more liberally-minded clinicians who valued the knowledge imparted by clinical encounters, which hampered the discipline's ability to gain speciality status and board certification from the AMA. ${ }^{73}$ Reflecting on the image problems faced by the discipline, AAA president William Sherman stated in 1958, the "more we isolate ourselves from the rest of the medical profession and stick strictly to one approach, the more likely they are going to consider us faddists." 74

Given these concerns, it is understandable that orthodox allergists accused food allergists of further tarnishing allergy's reputation. If allergists could be accused of faddism, then food allergists flirted with outright quackery. In an ardent article entitled "With What We Must Contend," an anonymous writer lambasted an "allergist" practicing in the northwest of the United States (likely Albert Rowe) for limiting a young girl's diet to “whole rice krisps, rye, rice, arrowroot, leaf lettuce with oil and white vinegar, string beans, spinach, banana, pear, apple juice, grape juice, sugar, salt, butter and (small quantities) of lamb and beef' in an effort treat her asthma, even though skin tests revealed allergies to cat hair, feathers, silk, and dust. 
The author contended not only that the patient's symptoms failed to improve on the diet, but also that infractions of the diet led to additional symptoms, demanding: "Why was the child made to follow an unbalanced diet of approximately ten foods for almost two years during which her infections increased in number and intensity? Why?"75

Food allergists were also criticized for not considering other approaches. In a 1945 review of Rowe's Elimination Diets and Patients' Allergies, for example, Leslie Gay, president of the SSAAC in 1927, argued that "the tendency toward a broad interpretation of the definition of allergy ... has frequently led to undue emphasis upon the prevalence of food allergy." Gay proceeded to chide Rowe for not considering "the psychosomatic side of human behavior" and its relation to allergy. According to Gay, "permanent relief is obtained when a thorough study of his home environment and of his many mental problems is made, and when these allimportant factors are adjusted." ${ }^{76} \mathrm{He}$ also questioned the dearth of psychosomatic factors in his criticism of Vaughan's Allergy: Strangest of All Maladies, contending that the “inexperienced or over-enthusiastic allergist confuses the digestive symptoms of a patient, who is nervous and harassed by financial or domestic problems, for gastro-intestinal or 'food" allergy.",77

While orthodox allergists were keen to consider the psychosomatic aspects of food allergy, following the Second World War, food allergists such as Theron Randolph increasingly looked to processed foods as possible triggers of allergy. Although such theories accorded with contemporary trends, evidenced by the passing of the Delaney Clause in 1958, which instituted the testing of food additives for possible carcinogenicity, and Rachel Carson's Silent Spring (1962), they further isolated food allergists from mainstream allergists. Recognizing that the gap between his conception of allergy and that of most conservative 
allergists had become impassable, Randolph formed the Society for Clinical Ecology in 1965. Clinical ecology, which stressed the environmental origins of unexplained chronic health problems, may have been topical and attractive to patients who were not finding succor with mainstream approaches, but it also gave more ammunition to skeptical allergists and the AAA.

An equally divisive development would occur the following year. This was the discovery of Immunoglobulin E (IgE), "the key antibody in the allergic response," by Kimishige and Teruka Ishizaka, two immunologists working in Colorado. ${ }^{78}$ IgE not only served as a marker for allergy, but its discovery also helped to bring allergy closer to immunology. IgE, which could be detected through the use of radioallergosorbent (RAST) tests, demarcated the chronic reactions to food, where IgE was typically absent, from the anaphylactic responses seen in peanut allergy, or what became known as "true" food allergy, where IgE was present. This delineation meant that food allergists who still described non-IgE reactions to food as food allergy, rather than food intolerance, were increasingly dismissed as being unscientific, tarnishing the reputation of a discipline that, through the identification of IgE, was finally becoming respectable.

Although orthodox allergists saw IgE as the ultimate identifier of food allergy, food allergists such as Randolph scoffed at this limited conception of allergy, describing its proponents as "blockheads." I9 IgE may have given allergy respectability, but for many clinicians and patients who still blamed food for their chronic conditions, it did not resolve the debates about food allergy. Nearly a decade after the discovery of IgE, a pair of articles in Pediatric Clinics of North America highlighted how the issues surrounding food allergy had not been resolved. On the one hand William Crook (1917-2002) described food allergy as the "Great 
Masquerader," blaming it for many childhood conditions, including hyperactivity, headaches, enuresis, gastrointestinal complaints, and respiratory problems. ${ }^{80}$ Allergist Charles May, however, disagreed:

In the absence of means for rigorous identification of the immunologic mechanisms, uncritical claims of relations of foods to symptoms can be expected, and unsupported "systems" of diagnosis and treatment will flourish. ... The afflicted and the uncritical will join in creating another quackery by resorting to some "system" as a crutch to hobble along with until better means of relief can be found. Rather than calling food "allergy" the "Great Masquerader" ... common to those overwhelmed with the trials and tribulations of life, this use of food "allergy" may be recognized as the Current Crutch. Such has been the story of quackery, and so it will always be until the last gaps in our knowledge are filled. ${ }^{81}$

Six decades after Raymond Hoobler cautiously suggested that food allergy might be the cause of common chronic complaints, allergists were still divided as to whether food allergy was the "Great Masquerader" or a form of "quackery."

\section{Conclusion}

Today, debates about food allergy tend to focus on how draconian the responses to anaphylactic allergies, such as peanut allergy, should be. Should the managers of Edmonton's Commonwealth Stadium ban peanut allergy when excess alcohol consumption has caused deaths at other Canadian football grounds? ${ }^{82}$ Should schoolchildren be prevented from having peanut butter, an inexpensive source of protein, energy, and fibre, because a small number of their classmates may mistakenly consume their sandwich? Although today's allergists may argue about the prevalence and cause of peanut allergy, they agree that it exists and is an important public health concern. Peanut allergy, in many ways, has allowed 
orthodox allergists to take ownership over food allergy, and the AAA has worked closely with both industry and patient groups to raise awareness of the conditions and prevent accidental exposures. But this does not mean that all questions about chronic food allergy have been answered.

Instead, interest in chronic food allergies has shifted from allergy to alternative health practitioners, such as clinical ecologists, chiropractors, and nutrition specialists. ${ }^{83}$ Although there is nothing inherently wrong with this - certainly many patients find the help they are seeking through these modalities - there remains the very real potential for abuse. Patients, desperate for a solution to their chronic health problems, particularly when conventional approaches have not been efficacious, may spend a great deal of money on tests, therapies, and advice that may or may not be legitimate. Indeed, the AAA has spent a great deal of effort during the last thirty years targeting dubious allergy tests, particularly "cytotoxic" testing, even going so far as to take legal action against its proponents. While it is important for the AAA to inquire about potentially fraudulent and dangerous practices, it is likely that this confrontational approach will do little to address lingering questions about the chronic reactions patients continue to have to common foods. What is the nature of the immunological reaction involved in chronic food allergy? What is the role of placebo in elimination diets? How does psychological stress affect immunological reactions? Have changes to our diet and our environment led to increasing rates of allergy? As allergic disease, including food allergy, continues to rise, perhaps allergists should instead employ a more nuanced, constructive, and less dogmatic approach to addressing these issues. 
Biographical Note

Dr. Matthew Smith is a Lecturer and Wellcome Trust Research Fellow at the University of

Strathclyde. He is a past winner of the Roy Porter Essay Prize, the Cadogan Prize and the

Pressman Burroughs-Wellcome Award for his research and writing. His first book, An

Alternative History of Hyperactivity: Food Additives and the Feingold Diet was published by

Rutgers University Press in 2011. His second book, Hyperactivity: The History of a

Children's Pandemic, will be published by Reaktion in 2012.

$\underline{\text { m.smith@strath.ac.uk }}$

16 Richmond Street

Glasgow

G1 1XQ

Acknowledgements

Many thanks to the Wellcome Trust for their generous support of this research. Thanks also to Mark Jackson for his encouragement and expertise, and to Gregg Mitman, Rima Apple, Matthias Reiss, and Michelle Smith for reading versions of this paper.

${ }^{1}$ Legislative Assembly of Ontario, Bill 3, Sabrina's Law, 2005, accessed July 2, 2010, http://www.ontla.on.ca/web/bills/bills detail.do?locale=en\&BillID=135; Barry Lank (director), Sabrina's Law (Lank/Beach Productions, 2007).

2 These reasons include increased consumption of peanut products, growing awareness of peanut allergy and allergies generally, and evermore antiseptic domestic environment, which has drastically reduced the exposure of children to previously common infectious diseases, such as polio and diphtheria, that previously trained their immune systems to react appropriately to threats from foreign proteins. Paul A. Davis et al, "Tree Nut and Peanut Consumption in Relation to Chronic and Metabolic Diseases Including Allergy," Journal of Nutrition 138 (2008): 1757S-62S; Saleh Al-Muhsen, Ann E. Clarke, and Rhoda S. Kagan, "Peanut Allergy: An Overview," Canadian Medical Association Journal 168 (2003): 127985.

${ }^{3}$ Food and Drug Administration, "Food Allergy Labeling and Consumer Protection Act of 2004” (Public Law 108-282, Title II), accessed July 2, 2010, 
http://www.fda.gov/Food/LabelingNutrition/FoodAllergensLabeling/GuidanceComplianceRe gulatoryInformation/ucm106187.htm; Canadian Food Inspection Agency, "Declaration of Food Allergens - Pre-Packaged Foods," accessed July 2, 2010, http://www.inspection.gc.ca/english/fssa/invenq/inform/allerge.shtml.

${ }^{4}$ Anonymous, "Peanut Allergy the Kiss of Death for Teenage Girl," November 26, 2005, accessed July 2, 2010,

http://www.canada.com/topics/bodyandhealth/story.html?id=1570c4d1-3153-41c0-856df46092f0afc1.

${ }^{5}$ Emily Cook, "Blood Donor Passed on Killer Nut Allergy," Daily Mirror, April 27, 2007, accessed July 2, 2010, http://www.mirror.co.uk/news/top-stories/2007/04/27/blood-donorpassed-on-killer-nut-allergy-115875-18971910/.

${ }^{6}$ D. M. Arnold, et al, "Passive Transfer of Peanut Hypersensitivity by Fresh Frozen Plasma," Archives of Internal Medicine 167 (2007): 853-4.

${ }^{7}$ Paul Steinbach, "Peanut-Free Galleries," Athletic Business June 2007, accessed July 2, 2010 http://athleticbusiness.com/articles/article. aspx?articleid=1555\&zoneid=37.

${ }^{8}$ For example, a colleague of mine in Exeter remarked to me recently that peanut products were banned from the child care facility his children attended.

${ }^{9}$ Peter Radetsky, Allergic to the Twentieth Century (Boston: Little, Brown and Company, 1997); Ilana Löwy, "On Guinea Pigs, Dogs and Men: Anaphylaxis and the Study of Biological Individuality, 1902-1939," Studies in History and Philosophy of Biological and Biomedical Sciences 34 (2003): 399-423; Carla Keirns, "Better Than Nature: The Changing Treatment of Asthma and Hay Fever in the United States, 1910-1945," Studies in History and Philosophy of Biological and Biomedical Sciences 34 (2003): 511-31; Gregg Mitman, "Hay Fever Holiday: Health, Leisure, and Place in Gilded-Age America," Bulletin of the History of Medicine 77 (2003): 600-35; Gregg Mitman, "Natural History and the Clinic: The Regional Ecology of Allergy in America," Studies in History and Philosophy of Biological and Biomedical Sciences 34 (2003): 491-510; Mark Jackson, Allergy: The History of a Modern Malady (London: Reaktion, 2006); Mark Jackson, “'Allergy con Amore’ Psychosomatic Medicine and the 'Asthmogenic Home' in the Mid-Twentieth Century," in Health and the Modern Home, ed. Mark Jackson (New York: Routledge, 2007), 153-74; Gregg Mitman, Breathing Space: How Allergies Shape Our Lives and Landscapes (London: Yale University Press, 2007); Mark Jackson, Asthma: The Biography (Oxford: Oxford University Press, 2009); Matthew Smith, An Alternative History of Hyperactivity: Food Additives and the Feingold Diet (New Brunswick, NJ: Rutgers University Press, 2011).

${ }^{10}$ Richard A. Cone and Emily Martin, "Corporeal Flows: The Immune System, Global Economies of Food and Implications for Health," The Ecologist 27 (1997): 107-11; Trevor Rous and Alan Hunt, "Governing Peanuts: The Regulation of the Social Bodies of Children and the Risks of Food Allergies," Social Science \& Medicine 58 (2004): 825-36. One exception is: Ian Mosby, “That Won-Ton Soup Headache': The Chinese Restaurant Syndrome, MSG and the Making of American Food, 1968-1980," Social History of Medicine 22 (2009): 133-51.

${ }^{11}$ Warwick Anderson, Myles Jackson, and Barbara Gutmann Rosenkrantz, "Toward an Unnatural History of Immunology," Journal of the History of Biology 27 (1994): 575-94.

${ }^{12}$ Jackson, Allergy, 10-11, 41.

${ }^{13}$ Francis C. Lowell and Irving W. Schiller, “Editorial: It Is So - It Ain't So," Journal of Allergy 25 (1954): 57. 
${ }^{14}$ William G. Crook, Walton W. Harrison, and Stanley E. Crawford, "Allergy - The Unanswered Challenge in Pediatric Research, Education and Practice," Pediatrics 21 (1958): 649.

${ }^{15}$ Crook, Harrison, and Crawford, "Allergy," 649-50.

${ }^{16}$ W. White Cooper, "Report of a Case of Poisoning from Eating Mussels (Mytelis Edulis)," Lancet 47 (1846): 275; Walter Fergus, "Idiosyncrasies," Lancet 94 (1869): 563; Anonymous, "Idiosyncrasy in Regard to Eggs," Lancet 153 (1899): 644.

${ }^{17}$ J. C. Dodds, "Idiosyncrasy Towards Eggs," JAMA 16 (1891): 827; Louis Fischer, "Milk Idiosyncrasies in Children," JAMA 39 (1902): 247-9.

${ }^{18}$ Italics in original. Henry Hyde Salter, "On Some Points in the Therapeutics and Clinical History of Asthma," Lancet 72 (1858): 472; Mark Jackson, Asthma: The Biography (Oxford: Oxford University Press, 2009), 93.

${ }^{19}$ McCall Anderson, "A Lecture on Nettle-Rash," BMJ 2 (1883): 1109; W. Allan Jamieson, "A Discussion of Diet in the Etiology and Treatment of Diseases of the Skin," BMJ 2 (1895): 1351-5.

${ }^{20}$ Stephen Mackenzie, "The Inaugural Address on the Advantages to be Derived from the Study of Dermatology," BMJ 1, (1896): 195.

${ }^{21}$ Mackenzie, "Inaugural Address," 196.

${ }^{22}$ Walter G. Smith, "Response to W. Allan Jamieson, 'A Discussion of Diet in the Etiology and Treatment of Diseases of the Skin,"” BMJ 2 (1895): 1353.

${ }^{23}$ Jamieson, "Discussion of Diet," 1351.

${ }^{24}$ Will C. Spain, "Review of Food Allergy by Herbert J. Rinkel, Theron G. Randolph and Michael Zeller," Quarterly Review of Biology 28 (1953): 97.

${ }^{25}$ Spain, "Review of Food Allergy," 98.

${ }^{26}$ W. Ray Shannon, "Neuropathic Manifestations in Infants and Children as a Result of Anaphylactic Reaction to Foods Contained in Their Dietary," American Journal of Disease of Children 24 (1922): 89-94; Anonymous, "Anaphylaxis in Certain Skin Diseases," JAMA 66 (1916): 1202-3; Anonymous "Eczema and Protein Hypersensitiveness," JAMA 67 (1916): 207; Charles J. White, "Two Modern Methods to be Employed in the Treatment of Chronic Eczema," JAMA 68 (1917): 81-9; Milton B. Cohen, "Pruritus of Anaphylactic Origin," JAMA 76 (1921): 377-8; Arthur F. Hurst, “An Address on Asthma," Lancet 197 (1921): 1113; George Piness and Hyman Miller, "Allergic Manifestations in Infancy and Childhood," Archives of Pediatrics 42 (1925): 557-62.

${ }^{27}$ H. J. Gerstenberger and J. H. Davis, "Report of a Case of Anaphylaxis Following an Intradermal Protein Sensitization Test," JAMA 76 (1921): 722. Others mentioned fatalities caused by skin testing for food allergies. R. W. Lamson, "So-Called Anaphylaxis in Man: With Especial Reference to the Diagnosis and Treatment of Clinical Allergies," JAMA 93 (1929): 1775-8.

${ }^{28}$ One reason for this was the lack of standardised extracts. Bret Ratner, "Diagnosis and Management of the Allergic Child," JAMA 96 (1931): 570-5.

${ }^{29}$ Johm H. Stokes, quoted in Howard Fox and J. Edgar Fisher, "Protein Sensitization in Eczema of Adults," JAMA 75 (1920): 910.

${ }^{30}$ Italics in original. Walter C. Alvarez, "Puzzling 'Nervous Storms' Due to Food Allergy," Gastroenterology 7 (1946): 252.

${ }^{31}$ Edward L. Pratt, "Food Allergy and Food Intolerance in Relation to the Development of Good Eating Habits," Pediatrics 21 (1958): 644.

${ }^{32}$ Albert H. Rowe and Albert Rowe, Jr., Food Allergy, (Springfield, Ill.: Charles C. Thomas, 1972 [1931]); Arthur C. Coca, Familial Nonreaginic Food-Allergy (Springfield, Ill.: Charles C. Thomas, 1943); Herbert Rinkel, Theron Randolph, and Michael Zeller, Food Allergy (Springfield, Ill.: Charles C. Thomas, 1950). 
${ }^{33}$ Spain, "Review of Food Allergy," 97.

${ }^{34}$ Italics in original. Walter R. Kessler, "Food Allergy,” Pediatrics 21 (1958): 523-4.

${ }^{35}$ Kessler, "Food Allergy," 525.

${ }^{36}$ Kessler, "Food Allergy," 525.

${ }^{37}$ Akira Morishima and Walter R. Kessler, "Food Hypersensitiveness? Report of Two Cases with Acute Constitutional Reactions," Pediatrics 29 (1962): 132-3.

${ }^{38}$ Von Pirquet quoted in Jackson, Allergy, 10; Pratt, "Food Allergy," 642.

${ }^{39}$ Jackson, Allergy, 56-7.

${ }^{40}$ Jackson, Allergy, 74. A century after Schofield's work, however, allergists at Cambridge have embarked upon an ambitious research project to desensitise children allergic to peanuts. A. T. Clark, S. Islam, Y. King, J. Deighton, K. Anagnostou, P. W. Ewan, "Successful Oral Tolerance Induction in Severe Peanut Allergy," Allergy 64 (2009): 1218-20.

${ }^{41}$ Edward Hollander, "Mucous Colitis Due to Food Allergy: With a Report of Five Cases," American Journal of the Medical Sciences 174 (1927): 495-500.

${ }^{42}$ Ratner, "Diagnosis and Management," 574.

${ }^{43}$ Ratner, "Diagnosis and Management," 575.

${ }^{44}$ Piness and Miller, "Allergic Manifestations," 560.

${ }^{45}$ For example, allergen extracts, antihistamines, and bronchiodilators. Jackson, Allergy, 103.

${ }^{46}$ Mitman, "Natural History and the Clinic," 494-500.

${ }^{47}$ Jackson, Allergy, 127-38.

${ }^{48}$ Jackson, Allergy, 134.

${ }^{49}$ Randolph, "Human Ecology," 526.

${ }^{50}$ Theron G. Randolph and Ralph W. Moss, An Alternative Approach to Allergies (New York: Lippincott and Crowell, 1980), 5.

${ }^{51}$ B. Raymond Hoobler, "Some Early Symptoms Suggesting Protein Sensitization in Infancy," American Journal of Diseases of Children 12 (1916): 135.

${ }^{52}$ Albert H. Rowe, Elimination Diets and the Patient's Allergies: A Handbook of Allergy, 2nd ed. (London: Henry Klimpton, [1941] 1944), 51.

${ }^{53}$ Rowe and Rowe, Jr., Food Allergy, ix.

${ }^{54}$ Warren Taylor Vaughan, Allergy: Strangest of All Maladies (London: Hutchinson's Scientific and Technical Publications 1942), 89.

${ }^{55}$ Warren Taylor Vaughan, "Minor Allergy: Its Distribution, Clinical Aspects and Significance," Journal of Allergy 5 (1935): 184-5.

${ }^{56}$ Vaughan, "Minor Allergy," 184.

${ }^{57}$ Vaughan, "Minor Allergy," 185.

${ }^{58}$ Jackson, Allergy, 120-4.

${ }^{59}$ Walter L. Winkenwerder, "Symposium on Food Allergy: The Internist's Viewpoint," Journal of Allergy 21 (1950): 487.

${ }^{60}$ Francis C. Lowell, "Clinical Papers for the Journal - Write and Wrong," Journal of Allergy 32 (1961): 544-5.

${ }^{61}$ Mitman, Breathing Space, 187-90, 200.

${ }^{62}$ Richard Mackarness, Not All in the Mind: How Unsuspected Food Allergy Can Affect Your Body and Your Mind (London: Pan Books, 1976), 62.

${ }^{63}$ Coca, Familial Nonreaginic Food-Allergy, 11.

${ }^{64}$ Coca, Familial Nonreaginic Food-Allergy, 117, 123, 145; Arthur C. Coca, The Pulse Test for Allergy (London: Max Parrish, 1959), 23, 57, 85, 117, 132, 143; L. N. Ettelson and Louis Tuft, "The Value of the Coca Pulse-Acceleration Method in Food Allergy," Journal of Allergy 32 (1961): 515. 
65 Theron G. Randolph, "Human Ecology and Susceptibility to the Chemical Environment," Annals of Allergy 19 (1961): 523.

${ }^{66}$ Mary Hewitt Loveless, "Allergy for Corn and its Derivatives: Experiments with a Masked Ingestion Test for its Diagnosis," Journal of Allergy 21 (1950): 500.

${ }^{67}$ Mackarness, Not All in the Mind, 11-13.

${ }^{68}$ Howard Markel, "The Cover," JAMA 283 (2000): 848.

${ }^{69}$ Robert A. Cooke, "Research in the Field of Allergy," Journal of Allergy 31 (1960): 273-82; Jackson, Allergy, 78. Coca and Cooke died within a year of each other in 1959 and 1960, respectively. Their juxtaposed obituaries in Journal of Allergy demonstrate that while Cooke's reputation as a founder of allergy was secure, Coca's work on food allergy had compromised his reputation. Attempting to sound gracious the author stated that some of Coca's "later views were not generally accepted, although their originality and his integrity in presenting them were recognized." Anonymous, "Obituary of Arthur Fernandez Coca," Journal of Allergy 31 (1960): 382; Anonymous, "Obituary of Robert Anderson Cooke," Journal of Allergy 31 (1960): 482-4.

${ }^{70}$ Rudolph L. Baer, “Correspondence,” Journal of Allergy 27 (1956): 483-4; Louis Webb Hill, "Editorial: Atopic Dermatitis," Journal of Allergy 27 (1956): 480-2; Louis Tuft, "Correspondence," Journal of Allergy 27 (1956): 293-4.

${ }^{71}$ Max Samter, "Presidential Address," Journal of Allergy 31 (1960): 91.

${ }^{72}$ Horace S. Baldwin and W. C. Spain, "Editorial,” Journal of Allergy 20 (1949): 388.

${ }^{73}$ Jackson, Allergy, 78.

${ }^{74}$ William B. Sherman, "President's Address," Journal of Allergy 29 (1958): 275.

75 Anonymous, "With What We Must Contend," Annals of Allergy 19 (1961): 193-5.

${ }^{76}$ Leslie M. Gay, "Review of Elimination Diets and Patient's Allergies: A Handbook of Allergy by Albert H. Rowe," Quarterly Review of Biology 20 (1945): 183.

${ }^{77}$ Leslie M. Gay, "Review of Strange Malady by Warren T. Vaughan," The Scientific Monthly 54 (1942): 280. For more on psychosomatic theories of allergy, see Jackson, "“Allergy Con Amore"”; Keirns, "Better than Nature."

${ }^{78}$ Mitman, Breathing Space, 193-4; K. Ishizaka, T. Ishizaka, M. M. Hornbrook, "Physicochemical Properties of Human Reaginic Antibody. IV. Presence of a Unique Immunoglobulin as a Carrier of Reaginic Activity," Journal of Immunology 97 (1966): 75-85.

${ }^{79}$ Jackson, Allergy, 200.

${ }^{80}$ Crook, "Food Allergy," 227, 232-5.

${ }^{81}$ Charles D. May, "Food Allergy: A Commentary," Pediatric Clinics of North America 22 (1975): 219.

${ }^{82}$ Anonymous, "Judge at Inquest Mulls Capping Beer Sales," accessed January 15, 2011, http://www.cbc.ca/canada/manitoba/story/2010/12/19/man-szabo-stadium-inquest-wrap.html. ${ }^{83}$ There are exceptions to this, particularly in the UK. See Jonathan Brostoff and Stephen J. Challacombe, Food Allergy and Intolerance $2^{\text {nd }}$ Ed. (London: Saunders, 2002). 